Journal of Molecular Genetics 3 (1): 1-4, 2011

ISSN: 2070-4267

(C) Medwell Journals, 2011

\title{
Construction of a Vector Containing Coding Sequence of Lipid Transfer Proten-2 (LTP2) Gene from Rice
}

\author{
${ }^{1}$ Mohammad Karimian, ${ }^{1}$ Mehran Miroliaie, ${ }^{1}$ Kamran Ghaedi, \\ ${ }^{1}$ Aliakbar Ehsanpour and ${ }^{2}$ Zohreh Zahraie \\ ${ }^{1}$ Department of Biology, Cell, Molecular and Developmental Biology Division, \\ School of Sciences, University of Isfahan, Isfahan, Iran \\ ${ }^{2}$ Department of Biology, Biotechnology Division, University of Kashan, Kashan, Iran
}

\begin{abstract}
Lipid Transfer Proteins (LTPs) are group of proteins with average molecular weight in plants that have potential applications especially in drug delivery systems. This research has been designed with the aim to construction of a vector containing coding sequence of Lipid Transfer Proten-2 (LTP2) gene from rice. There is no intron in rice LTP2 gene. In here, pGEX-6P-2 vector was used. First was extracted rice genome. Then, LTP2 gene was amplified with specific primers and PCR technique. In the next stage vector and LTP2 gene was digested with BamHI and XhoI restriction endonuclease enzymes. Then, digested vector and digested LTP2 gene were ligated in appropriate molar ratios.
\end{abstract}

Key words: LTP, electrophoresis, colony PCR, pGEX-6P-2 vector, enzymes, Iran

\section{INTRODUCTION}

Lipid transfer proteins are cystein-rich proteins capable of binding lipids and hydrophobic molecules, in vitro (Kader, 1975, 1996). Based on their molecular weight LTPs could be categorized into two classes: LTP1 (9 kd) and LTP2 (7 kd) (Lee et al., 1998; Shin et al., 1995). All of LTPs are highly stable proteins because they possess eight highly conserved cystein residues forming four disulfide bonds. Since, the activity of the lipid transfer is not specific these peptides are also called non-specific Lipid Transfer Proteins (nsLTPs) (Carvalho and Gomes, 2007).

Although, nsLTP are widely present in plants, their functions and regulations have not been fully understood. It has been implicated that plant nsLTP are involved in a variety of biological processes such as cutin formation, embryogenesis, defense reaction against symbiosis and plant adaptation to various environmental conditions (Wang et al., 2005). LTP are generally cationic proteins and some of themes have been isolated from plants. The nsLTP1 and nsLTP2 display an $\alpha$-helical fold stabilized by four disulfide binds (Douliez et al., 2001; Jose-Estanyol et al., 2004; Lin et al., 2005). Three dimensional structures of nsLTP1 from various sources were determined by X-ray and NMR spectroscopic techniques. The common feature of nsLTPs structure shows a hydrophobic cavity surrounded by four helices connected through disulfide binds. The hydrophobic cavity is the binding pocket for lipid or fatty acid molecules. nsLTP1s are well characterized where as the structure and functionality of nsLTP2s are understood (Pyee et al., 1994; Samuel et al., 2002; Liu et al., 2002). Plant nsLTPs are encoded by small multigene families. Coding region of the rice LTP1 gene and most other LTP genes, there is no intron in the rice LTP2 gene (Kalla et al., 1994; Arondel et al., 2000; Freddy et al., 2008). LTPs are stable to heat, denaturation agents and enzymatic digestion. Therefore, this protein can enter to the human homoral system and stimulate immune system. Therefore, this protein is food allergens (Mills et al., 2003; Salcedo et al., 2004). The antimicrobial activity of the LTPs was discovered by the screening of proteic extracted of plants in order to find proteins that could inhibit the growth of phytopatogens in vitro. Among the phytopatogens inhibited were bacteria and fungi however, the activity was stronger against fungi (Wang et al., 2004). These highly stable proteins can protect drug against oxidation or degradation therefore, LTPs can be used in drug delivery system (Pato et al., 2001 ). LTPs are suitable candidates to making biosensors (Choi et al., 2007). In here we isolated LTP2 gene from rice leaf. This gene inserted into pGEX-6p-2 vector and then this vector was transformed in $E$. coli (TOP10).

Corresponding Author: Mehran Miroliaie, Department of Biology, Cell, Molecular and Developmental Biology Division, School of Sciences, University of Isfahan, Hezar-Jerib Avenue, Azadi Square, Isfahan, Iran 


\section{MATERIALS AND METHODS}

Rice seeds: Rice seeds were purchase from Iran Rice Research Institute and were sterilized in 10\% calcium hypochlorite $(\mathrm{w} / \mathrm{v})$ solution and then immersed in water for 3 days. At room temperature rice seeds were germinated on moistened filter paper at room temperature.

DNA extraction solution and CTAB method: $C T A B$ method was used for DNA extraction from rice leaf. DNA extraction buffer comprise from $\mathrm{NaCl} 1.4 \mathrm{M}$, EDTA $20 \mathrm{mM}$, Tris (pH: 8.0) $100 \mathrm{mM}$ and CTAB 3\% w/v. Leaf tissue was harvested from plant and was placed in micro tube. Then, genome of rice was extracted by $\mathrm{CTAB}$ method (Ehsanpour et al., 2008).

Design of LTP primer: To design specific primers, the entire coning sequences of rice LTP2 were deduced from NCBI (Accession No. CT829990.1) and then analyzed with oligo 6 software. Specific primers pair were designed with introducing BamHI and XhoI sites at 5' end of forward and reverse primers, respectively. The forward primer sequence was: 5'-TAAGGATCCATGAGG-AAGTTGG CGGTGTT GGTG-3' and reverse primer sequence was: 5'TAACTCGAGTCAGTGGC-AGGTGGG-GAGGGC-3' (restriction sites are shown italics).

Hot start PCR: LTP is a GC rich gene therefore, designed primers form loops therefore, primers were added to PCR mixture at $98^{\circ} \mathrm{C}$. This method is hot start PCR. Materials which were used in the $25 \mu \mathrm{L}$ of PCR reaction are: $0 / 3 \mu \mathrm{L}$ Smar Taq polymerase $\left(5 \mathrm{u} \mu \mathrm{L}^{-1}\right), 0 / 3 \mu \mathrm{L}$ dNTPs mix $(10 \mathrm{mM}), 0 / 5 \mu \mathrm{L}$ forward and reverse primer $(5 \mathrm{pM}), 2 \mu \mathrm{L}$ $\mathrm{MgCl}_{2}(50 \mathrm{mM}), 5 \mu \mathrm{L}$ Betain $(5 \mathrm{M}), 2 / 5 \mu \mathrm{L}$ DMSO $(10 \%)$, $2 \mu \mathrm{L}$ Template $\left(600 \mathrm{ng} \mu \mathrm{L}^{-1}\right), 2 / 5 \mu \mathrm{L}$ AMS Buffer and up to $25 \mu \mathrm{L}$ with distilled water. For optimization of PCR, substances such as betaine, ammonium sulfate and dimethyl sulfoxide was used in PCR mixture. The reaction was carried out 30 cycles, each cycle consists of: denaturation temperature: $98^{\circ} \mathrm{C}$ for $1 \mathrm{~min}$, annealing temperature: $60^{\circ} \mathrm{C}$ for $1 \mathrm{~min}$ and extension temperature: $72^{\circ} \mathrm{C}$ for $1 \mathrm{~min}$.

Transformation of plasmid into the $E$. coli: LTP and pGEX-6p-2 was digestion by BamHI and XhoI. Then, DNA ligation was performed by DNA ligation kit (TaKaRa). Recombinant vector solution was transformed to $E$. coli competent cell. For this purpose $2 \mu \mathrm{L}$ from recombinant vector solution was added to the $100 \mu \mathrm{L}$ of E. coli competent cell. Solution was placed at $0^{\circ} \mathrm{C}$ for $30 \mathrm{~min}$ and then solution was placed in $42^{\circ} \mathrm{C}$ for $2 \mathrm{~min}$ then
$200 \mu \mathrm{L}$ LB liquid media was added to the solution and was incubated for $1 \mathrm{~h}$ in $37^{\circ} \mathrm{C}$. About $100 \mu \mathrm{L}$ from solution spread on a plate that contain LB solid media containing ampicilin. After overnight, recombinant colonies was formed on the surface of plate. Then grown colonies were checked by colony PCR using the vector specific primers. The primers pair were forward primer: 5'-GGGCTGGCAAGCCACGTTTGGTG-3' and reverse primer: 5'-CCGGGAGC TGCATG TGTCAGAGG-3'.

\section{RESULTS AND DISCUSSION}

DNA extraction: For verification of DNA extracting, $2 \mu \mathrm{L}$ from extracted DNA was loaded on agarose gel. Rice genome on agarose gel is shown in Fig. 1. Existing smear on gel suggests that DNA partially broken during the extraction.

Amplification of $L T P$ gene: At the end of PCR was produced $300 \mathrm{bp}$ DNA fragment that was the same with LTP gene length. Amplified fragments on agarose gel are shown in Fig. 2.

Transformation of recombinant vector to $E$. coli (TOP10): After digestion of LTP and pGEX-6p-2 vector by BamHI and XhoI were ligated with DNA ligation kit (TaKaRa). Recombinant vector solution was transformed to $E$. coli competent cell. After an overnight, recombinant colony was formed. Then was performed colony PCR.

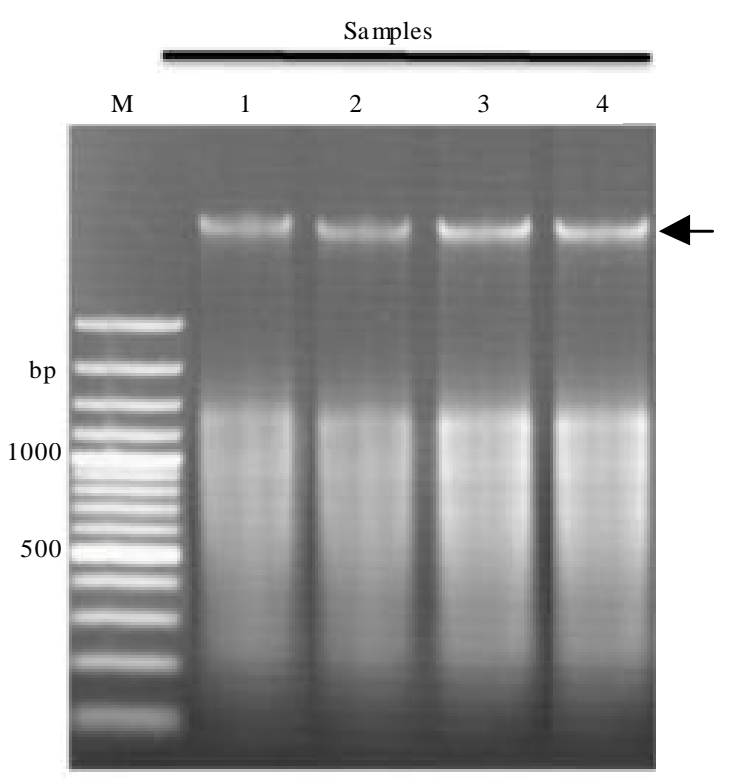

Fig. 1: Isolation from rice. Respected bands are shown by arrowhead. M: $100 \mathrm{bp}$ DNA ladder 


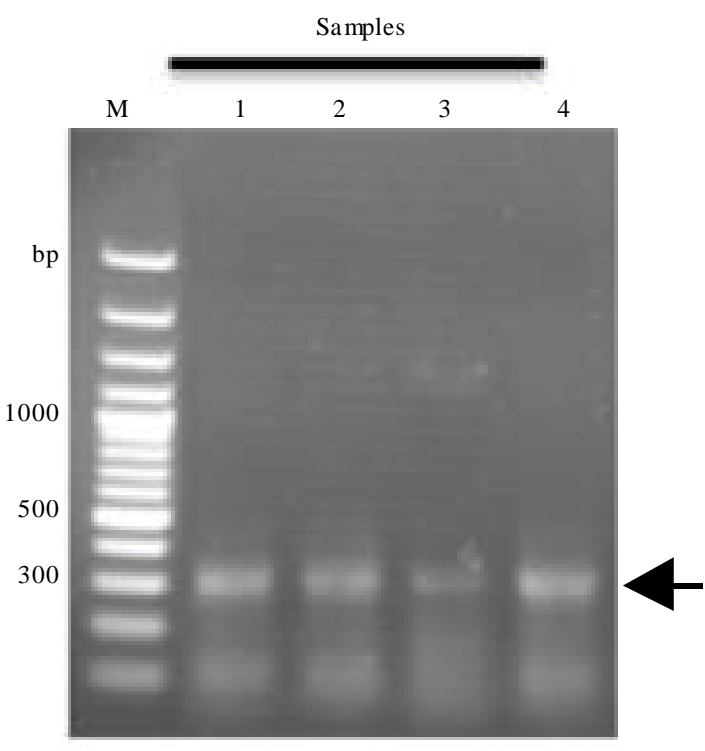

Fig. 2: Amplification of LTP2 CDS. PCR-product comprising the LTP2 CDS which is shown by arrowhead. M: 100 bp DNA ladder



Fig. 3: Colony PCR analysis of colonies after transformation by recombinant vector. The amplified band for positive colony is shown by arrowhead. M: 100 bp DNA ladder

Colony PCR: After transformation to ensure the formation of recombinant vectors and accuracy of transformation was performed colony PCR. Colony PCR products was loaded on $1 \%$ agarose gel. Data revealed colony of 1 was containing of recombinant vector (Fig. 3).

Elmorjani et al. (2004) cloned LTP gene of wheat (LTPW) by pETDP vector whereas we used pGEX-6p-2 vector that LTP gene was joined with GST tag in this vector. Carvalho et al. (2006) cloned LTP1 from mung beans in vector pCR2.1-TOPO. Due to intron in gene, RNA isolated from the seed tissue and then CDNA was made on. Due to the lack of introns in LTP2, rice genome of this plant was extracted and PCR reaction was performed on this template. Monnet et al. (2001) purified LTP2 from rice. In the present project because of installation GST tag at the beginning of gene will be facilitate protein purification. Choi et al. (2007) and Cheng et al. (2004), respectively research on LTP applications in drug delivery system and manufacturing the bio-sensor pGEX-6p-2/LTP expression vector construction makes the field for subsequent research as to create site directed mutagenesis in LTP and whereby changes in the structure of LTP to promote applications in drug delivery systems and manufacturing bio-sensors will be investigated. Salcedo et al. (2004) reported that LTP is a food allergen based on this, cloned protein can be purified and allergenic property of LTP2 will be investigated in vivo conditions.

The antimicrobial effect of LTP has been proven (Wang et al., 2004) that the researchers can investigate influence of recombinant bacteria extracts on desired microbes.

\section{CONCLUSION}

A recombinant vector was produced that was constructed from pGEX-6p- 2 vector and $L T P 2$ gene. This vector was transformed in the $E$. coli (topl 0 ). To ensure production recombinant vector and accuracy of transformation was performed colony PCR on transformed colony.

\section{REFERENCES}

Arondel, V., C. Vergenolle C. Cantrel and J.C. Kader, 2000. Lipid transfer proteins are encoded by a small multigene family in Arabidopsis thaliana. Plant Sci., 157: $1-12$.

Carvalho, A., G. Filho, B. Ferreira, A. Branco and I. Araujo et al., 2006. Cloning and characterization of a cowpea seed lipid transfer protein cDNA: Expression analysis during seed development and under fungal and cold stresses in seedlings' tissues. J. Plant Physiol. Biochem., 44: 732-742.

Carvalho, O.A. and M.V. Gomes, 2007. Role of plant lipid transfer proteins in plant cell physiology-A concise review. Peptides, 28: 1144-1153.

Cheng, C.S., M.N. Chen, Y.J. Liu, L.Y. Huang, K.F. Lin and P.C. Lyu, 2004. Evaluation of plant non-specific lipidtransfer proteins for potential application in drug delivery. Enzyme Microb. Technol., 35: 532-539. 
Choi, E., J. Mao and S.L. Mayo, 2007. Computational design and biochemical characterization of maize nonspecific lipid transfer protein variants for biosensor applications. J. Protein Sci., 16: 582-588.

Douliez, J.P., C. Pato, H. Rabesona, D. Molle and D. Marion, 2001. Disulfide bond assignment, lipid transfer activity and secondary structure of a $7-\mathrm{kDa}$ plant lipid transfer protein, LTP2. Eur. J. Biochem., 268: 1400-1403.

Ehsanpour, A.A., M. Tavassoli and L. Arab, 2008. Sex determinstion of Pistacia vera L. using ISSR markers. Malaysian Applied Biol., 37: 25-28.

Elmorjani, K., V. Lurquin, A. Lelion, H. Rogniaux and D. Marion, 2004. A bacterial expression system revisited for the recombinant production of cystinerich plant lipid transfer proteins. Biochem. Biophys. Res. Commun., 316: 1202-1209.

Freddy, B., C. Nathalie and G. Marie-Francoise, 2008. Genome-wide analysis of the rice and arabidopsis non-specific lipid transfer protein (nsLtP) gene families and identification of wheat nsLtP genes by EST data mining. BMC Genomics 9: 86-86.

Jose-Estanyol, M., F. Gomis-Ruth and P. Puigdomenech, 2004. The eight-cysteine motif, a versatile structure in plant proteins. J. Plant Physiol. Biochem., 42: $355-365$.

Kader, J.C., 1975. Proteins and the intracellular exchange of lipids. I. Stimulation of phospholipid exchange between mitochondria and microsomal fractions by proteins isolated from potato tuber. Biochim. Biophys. Acta., 280: 31-44.

Kader, J.C., 1996. Lipid-transfer proteins in plants. Annu. Rev. Plant Physiol. Plant Mol. Biol., 47: 627-654.

Kalla, R., K. Shimamoto, R. Potter, P.S. Nielsen, C. Linnestad and O.A. Olsen, 1994. The promoter of the barley aleurone-specific gene encoding a putative $7 \mathrm{kDa}$ lipid transfer protein confers aleurone cell-specific expression in transgenic rice. Plant J., 6: 849-860.

Lee, J.Y., K. Min, H. Cha, K. Y. Hwang and S.W. Suh, 1998. Rice nonspecific lipid transfer protein: The 1.6 a crystal structure in the unliganded state reveals a small hydrophobic cavity. J. Mol. Biol., 276: 437-448.
Lin, K.F., Y.N. Liu, S.T.D. Hsu, D. Samuel, C.S. Cheng, A.M. Bonvin and P.C. Lyu, 2005. Characterization and structural analyses of nonspecific lipid transfer protein 1 from mung bean. J. Biochem., 44: 5703-5712.

Liu, Y.J., D. Samuel, C.H. Lin and P.C. Lyu, 2002. Purification and characterization of a novel $7-\mathrm{kDa}$ non-specific lipid transfer protein-2 from rice (Oryza sativa). Biochem. Biophys. Res. Commun., 294: 535-540.

Mills, E.N.C., C. Madsen, P.R. Shewry and H.J. Wichers, 2003. Food allergens of plant origin-their molecular and evolutionary relationships. J. Trends Food Sci. Technol., 14: 145-156.

Monnet, F.P., W. Dieryck, F. Boutrot, P. Joudrier and M.F. Gautier, 2001. Purification, characterisation and cDNA cloning of a type $2(7 \mathrm{kDa})$ lipid transfer protein from Triticum durum. Plant Sci., 161: 747-755.

Pato, C., M. Le Borgne, G. Le Baut, P. Le Pape, D. Marion and J.P. Douliez, 2001. Potential application of plant lipid transfer proteins for drug delivery. Biochem. Pharmacol., 62: 555-560.

Pyee, J., H. Yu and P.E. Kolattukudy, 1994. Identification of a lipid transfer protein as the major protein in the surface wax of broccoli (Brassica oleracea) leaves. Arch. Biochem. Biophys., 311: 460-468.

Salcedo, G., R. Sanchez-Monge, A. Diaz-Perales, G. Garcia-Casado and D. Barber, 2004. Plant nonspecific lipid transfer proteins as food and pollen allergens. J. Clin. Exp. Allergy, 34: 1336-1341.

Samuel, D., Y.J. Liu, C.S. Cheng and P.C. Lyu, 2002. Solution structure of plant nonspecific lipid transfer protein-2 from rice (Oryza sativa). J. Biol. Chem., 277: 35267-35273.

Shin, D.H., J.Y. Lee, K. Y. Hwang, K.K. Kim and S.W. Suh, 1995. High resolution crystal structure of the non-specific lipid transfer protein from maize seedlings. J. Struct., 3: 189-199.

Wang, S.Y., J.H. Wu, T.B. Ng, X.Y. Ye and P.F. Rao, 2004. A non-specific lipid transfer protein with antifungal and antibacterial activities from the mung bean. Peptides, 25: 1235-1242.

Wang, Z., W. Xie, F. Chi and C. Li, 2005. Identification of non-specific lipid transfer protein-1 as a calmodulinbinding protein in Arabidopsis. FEBS Lett., 579: 1683-1687. 